\title{
Increased Incidence of Endometrial Cancer Following the Women's Health Initiative: An Assessment of Risk Factors
}

\author{
Ginger D. Constantine, MD, ${ }^{1}$ Grant Kessler, BA, ${ }^{2}$ Shelli Graham, $\mathrm{PhD},{ }^{3}$ and Steven R. Goldstein, MD ${ }^{4}$
}

\begin{abstract}
Background: The Surveillance, Epidemiology, and End Result (SEER) database shows a variable increase in endometrial cancer incidence over time. The objective of this review was to examine published endometrial cancer rates and potential etiologies.

Methods: Endometrial cancer incidence was obtained from the SEER Program database from 1975 through 2014, and a test for trend in incidence was calculated. Changes in risk factors thought to be associated with endometrial cancer, including age, obesity, diabetes, diet and exercise, reproductive factors, and medications (hormone therapy [HT] including Food and Drug Administration [FDA]-approved and non-FDA-approved [compounded] estrogens and progestogens, tamoxifen, and hormonal contraceptives) were found through PubMed searches. Temporal trends of risk factors were compared with endometrial cancer trends from SEER. Results: Although endometrial cancer rates were constant from 1992 to 2002 (women 50-74 years of age), they increased $2.5 \%$ annually with a $10 \%$ increase from 2006 to 2012 (trend test 0.82 ). Use of approved prescription estrogen-progestogen combination products decreased after the publication of the Women's Health Initiative (WHI) data, whereas other risk factors either remained constant or decreased during the same time; however, compounded bioidentical HT (CBHT) use increased coincident with the endometrial cancer increase.

Conclusion: Endometrial cancer rate increases after the first publication of WHI data in 2002 may be associated with the decreased use of approved estrogen-progestogen therapy, the increase in CBHT use, and the prevalence of obesity and diabetes; potential relationships require further evaluation.
\end{abstract}

Keywords: compounded bioidentical hormone therapy, endometrial cancer, hormone therapy, menopause

\section{Introduction}

$\mathbf{I}$

N THE United States, uterine cancer is the fourth leading cancer among women, representing $7 \%$ of all new cancer cases. ${ }^{1}$ In 2017, 61,000 new uterine cancer diagnoses were estimated and nearly 11,000 women were estimated to die from the disease, primarily affecting postmenopausal women (mean age of diagnosis, 62 years). ${ }^{2}$ The greatest percentage of new cases by age from 2010 to 2014 was detected in women around and after menopausal age $(16.7 \%$ for $45-54$ years of age, $34.5 \%$ for $55-64$ years, and $25.8 \%$ for $65-74$ years). ${ }^{2}$

The Surveillance, Epidemiology, and End Result (SEER) Program of the National Cancer Institute collects and pub- lishes cancer incidence and survival data from populationbased cancer registries covering $\sim 28 \%$ of the U.S. population. ${ }^{3}$ Data from SEER show variable increases in endometrial cancer incidence over time, with sharper incident increases in black women compared with white women. ${ }^{4}$ Another report found the incidence to increase over time in women 50-74 years of age (annual percentage change 2004-2009: 2.8\%; 2005-2009: 3.3\%; and 2006-2009: 4.2\%), ${ }^{5}$ after publication of the Women's Health Initiative (WHI) data. ${ }^{6}$

When the balance of progesterone and estrogen shifts at the time of menopause, with a decrease in progesterone production, even small amounts of circulating estrogens may not be adequately counterbalanced, and can lead to the

\footnotetext{
${ }^{1}$ EndoRheum Consultants, LLC, Malvern, Pennsylvania.

${ }^{2}$ Consultant to EndoRheum Consultants, LLC, Malvern, Pennsylvania.

${ }^{3}$ TherapeuticsMD, Boca Raton, Florida.

${ }^{4}$ Department of Obstetrics and Gynecology, New York University School of Medicine, New York, New York.
}

(c) Ginger D. Constantine et al. 2018; Published by Mary Ann Liebert, Inc. This Open Access article is distributed under the terms of the Creative Commons License (http://creativecommons.org/licenses/by/4.0), which permits unrestricted use, distribution, and reproduction in any medium, provided the original work is properly cited. 
thickening of the endometrium and potential subsequent endometrial cancer. ${ }^{7}$ Several studies have demonstrated that unopposed estrogen therapy increased the risk for endometrial hyperplasia and cancer, whereas the addition of a progestogen prevents such risk. ${ }^{8-14}$

In addition to the use of menopausal hormone therapy (HT), a number of factors may influence a woman's risk of developing endometrial cancer, including certain medications, obesity, diabetes, reproductive factors, and diet and exercise. ${ }^{7}$ In this study, using publicly available cancer incidence statistics in SEER, we review and quantitatively describe the trend of endometrial cancer incidence in recent years. We also compare the trends in risk factors potentially associated with type I endometrial cancer risk with the incidence rates over time to explore whether these risk factor changes could explain the increase in endometrial cancer observed between 2002 and 2014.

\section{Methods}

Data on endometrial cancer incidence were extracted from January 1975 through December 2014 from the SEER Program database (November 2016 data submission; April 2017 release date). ${ }^{15}$ Informed consent was not applicable since the study was based on a publicly available database. The change in the age-adjusted endometrial cancer incidence from 2006 to 2012 was calculated using a test for trend. Change in the incidence of risk factors for endometrial cancer was then reviewed and compared with the change in SEER incidence of endometrial cancer.

PubMed was searched by two separate individuals to obtain trend data on the following potential risk factors for endometrial cancer: age, obesity (defined as body mass index $[\mathrm{BMI}]$ of $\geq 30 \mathrm{~kg} / \mathrm{m}^{2}$ ), medications (HT, including Food and Drug Administration [FDA]-approved and non-FDA-approved [compounded] estrogens and progesterone, tamoxifen, and hormonal contraceptives), diabetes, reproductive factors, diet, and exercise. Search terms included endometrial cancer combined with terms relevant for the mentioned risk factors. The temporal trends of these risk factors potentially associated with endometrial cancer were compared with the endometrial cancer incidence trends.

\section{Results}

\section{Endometrial cancer incidence in the SEER database}

Data from SEER showed that endometrial cancer rates declined between 1975 and 1992, and then remained relatively constant up to 2002 in women 50 years of age or older (Fig. 1A). ${ }^{4}$ Extracting data from the SEER database, we calculated that the age-adjusted incidence rate per 100,000 people increased $2.5 \%$ annually with a $10 \%$ increase from 2006 to 2012 , post-WHI trial (test for trend $0.82, R^{2}=0.65$; Fig. 1B).

\section{Menopausal HT}

Decrease in FDA-approved estrogen and progesterone therapies. Increased risk for endometrial cancer was unequivocally shown in earlier studies of unopposed oral estrogen. ${ }^{16-19}$ A rising incidence of endometrial cancer was also reported after estrogen therapy first became commonly used to treat menopausal symptoms and as use increased in the 1970 s. $^{20}$ Early data also showed that addition of a pro-
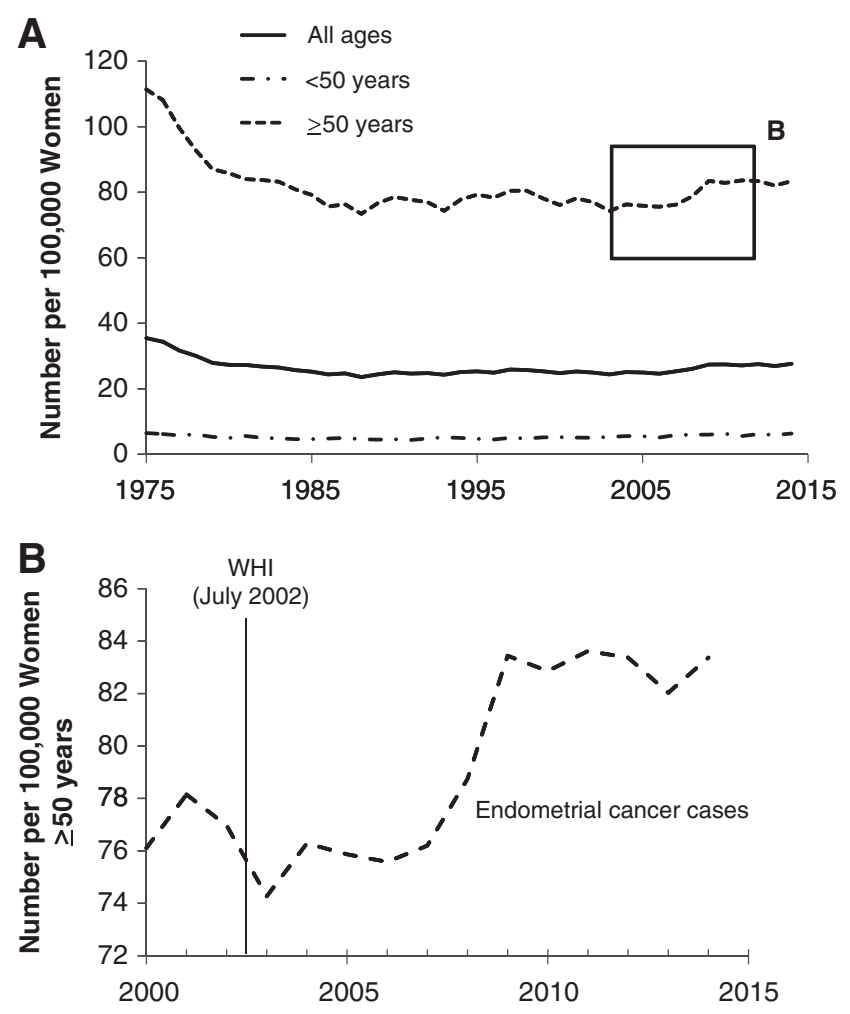

FIG. 1. Age-adjusted endometrial cancer incidence per 100,000 from SEER for (A) all women between 1975 and 2014 and (B) in women $\geq 50$ years for 2000-2014. ${ }^{4}$ SEER, Surveillance, Epidemiology, and End Result.

gestogen prevented the increased risk of endometrial cancer with unopposed estrogens. ${ }^{18,19}$ Later studies confirmed this association, ${ }^{11,21}$ including data from the WHI showing a decrease in endometrial cancer with continuous estrogen plus progestogen compared with placebo. ${ }^{22}$ Currently, women with a uterus taking systemic estrogens (oral/transdermal) are to be prescribed a progestogen to prevent endometrial hyperplasia, and the potential for subsequent endometrial cancer. ${ }^{23}$

After the first publication of the WHI findings, ${ }^{6}$ prescriptions of FDA-approved HT significantly decreased among postmenopausal women. ${ }^{24,25}$ Before the WHI publication, annual HT use had increased from 58 million prescriptions in 1995 to 90 million prescriptions in 1999 and remained stable through June 2002. ${ }^{26}$ Within 1 year of the WHI publication, use of prescribed HT sharply declined to the levels of $1995,{ }^{26}$ and continued to decline until 2009 (Fig. 2). ${ }^{25}$ The authors of one study suggest that the increased incidence of endometrial cancer observed after 2002 may possibly be linked to the decreased use of menopausal HT with a progestogen. ${ }^{5}$

Increase in FDA-approved vaginal estrogens. Medical societies have suggested that the use of a progestogen is not always required with vaginal estrogens as local vaginal estrogen use has not been associated with increased risk of endometrial cancer, ${ }^{27-30}$ and does not result in endometrial hyperplasia rates as reported for systemic unopposed estrogens. However, large long-term studies of vaginal estrogens are lacking. Although use of vaginal estrogens almost doubled from 2000 to 2009 (Fig. 2) and later decreased from 2011 through $2015,{ }^{25,31}$ clinical trials and observational 


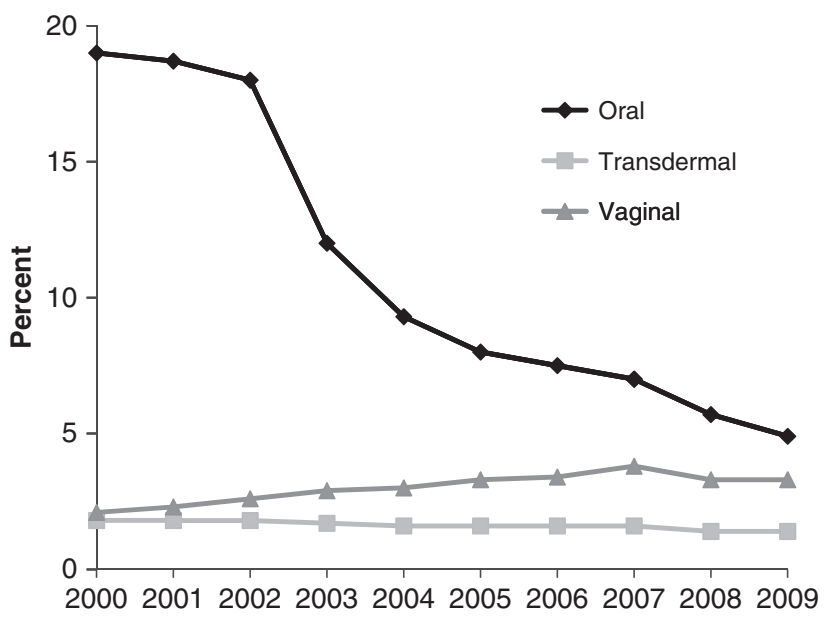

FIG. 2. Prevalence of women using hormone therapy by formulation between 2000 and 2009. ${ }^{25}$

studies of vaginal estrogen use have not found an association with endometrial cancer. ${ }^{27-30,32}$ Therefore, it is unlikely that vaginal estrogens contribute to the increase in endometrial cancer observed between 2002 and 2009.

Increase in compounded bioidentical HT. Compounded bioidentical HT (CBHT), which is not FDA-approved and is inadequately regulated by the FDA, is another form of menopausal HT. Clinicians have noticed a precipitous increase in the use of CBHT since the publication of the WHI findings, although quantifying that increase has been challenging since CBHT use is not systematically tracked and available material on the magnitude of its use is limited. ${ }^{33-35}$ However, some recent publications have estimated CBHT use and have reported an increase in its use. Two smaller surveys ( $n=160$ responders in each) by the same authors showed an increase of $23 \%$ in any compounding prescription from 2005 to $2006 .^{36,37}$ In a 2012-2013 analysis of a large national prescription claims database ( $>22$ million members), a $27 \%$ increase in the use of any compounded medication and a $34 \%$ increase in claims for the same were observed from 2012 to 2013, and CBHT was the most commonly compounded therapy among women aged 40-69 years, with this gender and age group using compounded therapies most frequently. ${ }^{38}$ A 2014 survey of compounding and independent community pharmacists reported that their compounding business had grown or stayed the same in the past 2 years, and most expected continued growth, anticipating 5\%-25\% growth of CBHT use over the next 2 years. ${ }^{39}$ A study, based on two surveys conducted in 2013 and 2014, estimated that 1-2.5 million women older than 40 years of age may be using CBHT a year (an estimated 21-39 million prescriptions). ${ }^{40}$ Finally, a 2015 North American Menopause Society survey reported that $35 \%$ of U.S. women currently using HT (and $41 \%$ of ever users aged $40-49$ years) are using CBHT. ${ }^{41}$

The incidence of endometrial hyperplasia with $\mathrm{CBHT}$ has not been rigorously studied as with FDA-approved HTs. The levels of progesterone in CBHT, as in any HT, must be high enough to counter any endometrial stimulation by estrogens. Some cases of endometrial cancer and endometrial hyperplasia, ${ }^{41-44}$ as well as higher rates of vaginal bleeding, ${ }^{41}$ have been reported among healthy CBHT users.

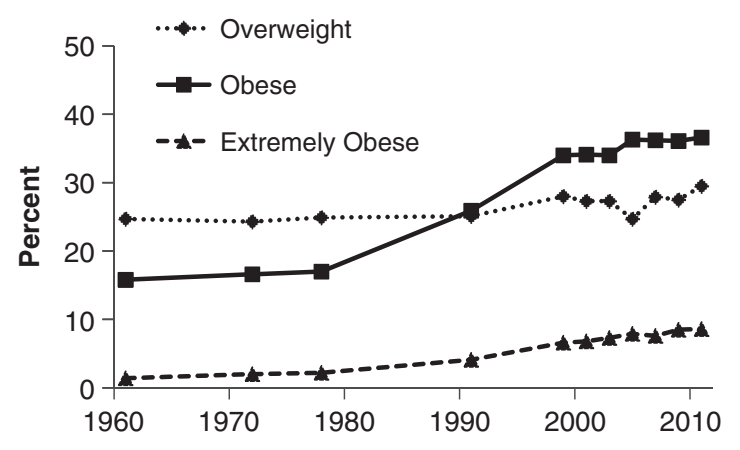

FIG. 3. Age-adjusted prevalence of overweight (BMI 25 to $<30 \mathrm{~kg} / \mathrm{m}^{2}$ ), obese (BMI $\geq 30 \mathrm{~kg} / \mathrm{m}^{2}$ ), or extremely obese (BMI $\geq 40 \mathrm{~kg} / \mathrm{m}^{2}$ ) women $20-74$ years of age between 1960 and $2012 .{ }^{50}$ BMI, body mass index.

The increase in CBHT use is consistent with the increased incidence of endometrial cancer after the WHI in 2002, implicating a potential role for $\mathrm{CBHT}$ in this endometrial cancer increase.

\section{Obesity}

Obesity may account for up to $40 \%$ of the observed endometrial cancer incidence, with obese women having a twofold to fivefold increased risk of developing endometrial cancer compared with normal weight women. ${ }^{45-47}$ In general, obesity is associated with higher levels of circulating estrogens in postmenopausal women, ${ }^{48,49}$ likely accounting for their increased risk of endometrial cancer. In the United States, the age-adjusted prevalence of obesity (body mass index $[\mathrm{BMI}] \geq 30 \mathrm{~kg} / \mathrm{m}^{2}$ ) in women remained stable from 1960 and 1980, which was followed by a sharp increase between 1980 and 1999 (Fig. 3). ${ }^{50}$ From 1999 to 2014, the prevalence of obesity increased among all women, including women who were $45-64$ and $\geq 65$ years ${ }^{51}$; however, this increase was minimal and of smaller magnitude compared with the increase in endometrial cancer. A role for obesity in the increased incidence of endometrial cancer after WHI is not likely (or a very small contributor), given its much smaller change in prevalence over the same time period.

\section{Diabetes}

Diabetes has also been associated with a significant increased risk of endometrial cancer. ${ }^{52}$ Data based on the $\mathrm{Na}$ tional Health Interview Survey (NHIS) showed that the prevalence of diabetes in women increased between 1990 and 2008 , before leveling off with no significant change between 2008 and $2012 .{ }^{53}$ U.S. adults aged $\geq 65$ years were twice as likely to have diabetes $(26.9 \%$ vs. $13.7 \%)$ than younger adults (45-64 years) from 2005 to $2008 .{ }^{54}$ Although these data suggest that the increase in diabetes observed may have contributed to the increase in endometrial cancer incidence, it would not explain the abrupt increase observed between 2002 and 2009 and maintained through 2014.

\section{Reproductive factors}

Certain reproductive factors may also influence the incidence of endometrial cancer by affecting the relative 
estrogen/progesterone balance. ${ }^{55}$ Women with an increased lifetime exposure to estrogens, including women with an early age at menarche, later age at menopause, lower parity, and no history of oral contraceptive use, have been linked to a higher incidence of endometrial cancer. ${ }^{45,55-57}$

Overall, all of these reproductive factors have remained fairly constant during the time of observed endometrial cancer increase. The age of menarche has remained relatively the same over the past 40 years in the Unites States, although the age of thelarche seems to be occurring earlier. ${ }^{58,59}$ Data from the 2012 American Community Survey and Birth Record Data from Vital Statistics show that although the number of children born per woman decreased between 1976 and 1992, the rate remained fairly uniform between 1992 and 2012. ${ }^{60}$

Use of oral contraceptives reported by the National Survey of Family Growth also shows fairly constant use between 1982 and 2008, with rates of $15.6 \%$ in $1982,17.3 \%$ in 1995 , $18.9 \%$ in 2002 , and $17.3 \%$ between 2006 and $2008 .{ }^{61}$ A later analysis of this database showed no significant change in the prevalence of oral contraceptive use from 2008 to 2014 . $^{62}$ Despite this stable prevalence, a change in oral contraceptive formulations resulting in lower progesterone relative to estrogen could potentially increase endometrial cancer risk. However, the dominant trend in formulation changes for oral contraceptives has been a decrease in estrogen rather than a decrease in progesterone. Furthermore, oral contraceptives are well known to reduce the risk of endometrial cancer, with risk reduction that increases with duration of use and persists up to 30 years after their discontinuation. ${ }^{63-65}$

Intrauterine devices (IUDs) were shown to have a protective effect against endometrial cancer, which is increased with duration of use, and sustained up to 5 years after cessation of use. ${ }^{66,67}$ National Survey of Family Growth data have shown a high increase in the popularity of long-acting reversible contraceptives (LARCs; IUDs and implants) in women aged 15-44 years between 1982 and $2013 .{ }^{68}$ Usage of LARCs was constant between 1998 and 2002 (1.5\%); current LARC use then doubled in 2006-2010 (3.8\%) and then nearly doubled for 2011-2013 (7.2\%). ${ }^{68}$ No studies have yet reported whether newer types of IUDs that release progesterone have any effect on endometrial cancer risk; however, these IUDs are sometimes used to treat precancers and early endometrial cancers. $^{69}$

Based on the described trends, reproductive factors do not appear to be major contributors to the increase of endometrial cancer incidence after WHI.

\section{Cancer and cancer-related treatments}

Although rare, there are certain types of cancers that have estrogen-secreting capabilities and may contribute to endometrial tissue stimulation. Granulosa cell tumors (GCTs) of the ovary represent $\sim 5 \%$ of all ovarian malignancies, and adult GCTs occur primarily in perimenopausal or early postmenopausal women. ${ }^{70}$ Evidence suggests that GCTs secrete increased levels of estradiol, and elevated estradiol serum levels may be responsible for disease progression and clinical manifestations of other diseases. ${ }^{70}$ Nevertheless, in addition to the low occurrence of GCTs of the ovary, there has been an overall decrease in invasive ovarian cancer in women $\geq 65$ years from $52.5 \%$ in 1998 to $41.6 \%$ in $2014,{ }^{71}$ suggesting that this risk factor would not contribute to the observed increase in endometrial cancer incidence.

Cancer-related treatments, such as the selective estrogen receptor modulator tamoxifen, may also affect endometrial cancer risk. Although effective in reducing breast cancer incidence by acting as an antiestrogen in breast tissue, evidence suggests that tamoxifen acts as an estrogen in the uterus and increases endometrial cancers. ${ }^{7,72}$ Despite the increased risk of tamoxifen use with endometrial cancer, tamoxifen use has decreased since 2000 and thus is unlikely to be a significant risk factor. ${ }^{73}$

\section{Exercise}

Epidemiological evidence has shown that physical activity can lower the risk of endometrial cancer by $20 \%-40 \%$ compared with physical inactivity. ${ }^{74-76}$ To date, the prevalence of leisure-time physical inactivity has gradually declined over the past three decades in most U.S. states; however, rates of physical inactivity remain substantially high. ${ }^{77}$ Based on these data, the small changes observed in exercise among U.S. adults may not have significantly affected overall endometrial cancer incidence after WHI.

\section{Discussion}

Owing to the significant increase in endometrial cancer incidence observed post-WHI, we investigated the potential contribution of each risk factor to this increased incidence. As reviewed here and as suggested by others, changes in the prevalence of known endometrial cancer risk factors seemed unlikely to account for the increase in endometrial cancer incidence. ${ }^{5}$ Our data review demonstrates a decrease in the use of FDA-approved estrogen plus progestogen HT (known to protect the endometrium), which has been shown to be associated with an increase in endometrial cancer risk. Thus, this decrease may be a contributing factor to the increased endometrial cancer incidence after the WHI. Similarly, the increase in CBHT use may also increase the incidence of endometrial cancer, with obesity and diabetes contributing to the increase in incidence but likely to a much lesser degree.

Unlike manufactured FDA-approved HT, ${ }^{40,41} \mathrm{CBHT}$ is not approved nor regulated by the FDA and, therefore, does not carry the safety warnings mandated for all HTs by the FDA after the WHI. ${ }^{78}$ Since it also lacks standard guidelines set forth by the FDA, under- and overdosage of CBHT are possible due to its inconsistent bioavailability and bioactivity. ${ }^{35}$ The variability in purity and quality of progesterone products was examined and two out of five progesterone samples (40\%) tested failed repeat potency testing and one sample $(20 \%)$ failed uniformity testing (consistent dosages), leading to underdosing with progesterone. ${ }^{79}$ Another sampling of compounded progesterone vaginal suppositories from 10 randomly chosen pharmacies found that half $(5 / 10)$ of the pharmacies provided product that was subpotent or superpotent (outside of the $90 \%-110 \%$ acceptable range). ${ }^{80}$ Similarly, CBHT prescriptions from 12 sources had superpotent estradiol or estrone (up to $>250 \%$ ) and subpotent progesterone $(60 \%-$ $80 \%$ ) in a small investigation by one physician. ${ }^{81}$ Although we cannot be certain that these small studies of CBHT potency are representative of most CBHT being used, there is still cause for concern given the considerable risks: underdosing of progesterone and/or overdosing of estrogens could 
lead to an increased risk of endometrial hyperplasia and cancer, overdosing of estrogens to an increased risk of venous thromboembolism, and underdosing of estrogens to an increased risk of osteoporosis. ${ }^{35}$

In addition, numerous claims regarding CBHT in comparison with FDA-approved HT products have been noted; however, none of them have been supported by scientific evidence, and clinicians should carefully consider each claim with caution before prescribing CBHT. ${ }^{35,82,83}$ The lack of reliable placebo- or comparator-controlled studies evaluating CBHT makes it difficult to accurately assess CBHT efficacy or safety. As stated by the American College of Obstetricians and Gynecologists, the North American Menopause Society, the Endocrine Society, and the American Society for Reproductive Medicine, CBHT poses additional risk to its users due to its variable purity, potency, and lack of efficacy and safety data ${ }^{23,35,78,84}$ and, therefore, should be avoided unless medically indicated (dosing or formulation not available or allergy to FDA-approved products). ${ }^{23}$ Patients and physicians should equally educate themselves on the risks and benefits of CBHT, and physicians should be cautious in prescribing CBHT due to the perceived risk of increasing endometrial cancer risk. Women currently taking CBHT should also receive regular endometrial surveillance as a safety precaution.

In conclusion, an increase in endometrial cancer incidence may be associated with a number of risk factors, including increased CBHT use, obesity, and diabetes, as well as decreased use of approved estrogen-progestogen HT. We believe that CBHT use to be the most likely significant risk factor for the observed increase in endometrial cancer postWHI. Additional studies are needed to fully assess unapproved CBHT as a risk factor for endometrial cancer and to further explore the significant health implications of CBHT use in postmenopausal women.

\section{Acknowledgments}

The authors appreciate the medical writing assistance provide by Dominique Verlaan, $\mathrm{PhD}$, of Precise Publications, LLC, which was supported by TherapeuticsMD.

\section{Author Disclosure Statement}

TherapeuticsMD supported the medical writing assistance provided by Dominique Verlaan, $\mathrm{PhD}$, of Precise Publications, LLC. G.D.C. is a consultant to multiple pharmaceutical companies including but not limited to TherapeuticsMD, G.K. is a consultant to EndoRheum Consultants, S.G. is an employee of TherapeuticsMD with stock/stock options, S.R.G. is on advisory boards for AbbVie, Allergan, and TherapeuticsMD; and Philips Ultrasound Equipment Loan.

\section{References}

1. Siegel RL, Miller KD, Jemal A. Cancer statistics, 2018. CA Cancer J Clin 2018;68:7-30.

2. National Cancer Institute (NIH). Cancer Stat Facts: Endometrial Cancer. Available at: https://seer.cancer.gov/ statfacts/html/corp.html Accessed November 27, 2017.

3. National Cancer Institute (NIH). Overview of the SEER program. Available at: https://seer.cancer.gov/about/overview .html Accessed November 27, 2017.

4. Howlader N, Noone AM, Krapcho M, et al. SEER Cancer Statistics Review 1975-2014; Cancer of the Corpus and
Uterus. National Cancer Institute. Bethesda, MD Available at: https://seer.cancer.gov/csr/1975_2014/results_single/sect_07_ table. 01.pdf, based on November 2016 SEER data submission, posted to the SEER website, April 2017. Accessed August 2, 2017.

5. Wartko P, Sherman ME, Yang HP, Felix AS, Brinton LA, Trabert B. Recent changes in endometrial cancer trends among menopausal-age U.S. women. Cancer Epidemiol 2013;37:374-377.

6. Rossouw JE, Anderson GL, Prentice RL, et al. Risks and benefits of estrogen plus progestin in healthy postmenopausal women: Principal results From the Women's Health Initiative randomized controlled trial. JAMA 2002;288:321-333.

7. American Cancer Society. Endometrial cancer causes, risk factors, and prevention. Available at: https://www.cancer.org/ content/dam/CRC/PDF/Public/8610.00.pdf Accessed November 27, 2017.

8. Grady D, Gebretsadik T, Kerlikowske K, Ernster V, Petitti D. Hormone replacement therapy and endometrial cancer risk: A meta-analysis. Obstet Gynecol 1995;85:304-313.

9. Furness S, Roberts H, Marjoribanks J, Lethaby A. Hormone therapy in postmenopausal women and risk of endometrial hyperplasia. Cochrane Database Syst Rev 2012:CD000402.

10. Sjogren LL, Morch LS, Lokkegaard E. Hormone replacement therapy and the risk of endometrial cancer: A systematic review. Maturitas 2016;91:25-35.

11. Writing Group for the PEPI Trial. Effects of hormone replacement therapy on endometrial histology in postmenopausal women. The Postmenopausal Estrogen/Progestin Interventions (PEPI) trial. JAMA 1996;275:370-375.

12. Million Women Study C. Endometrial cancer and hormonereplacement therapy in the Million Women Study. Lancet 2005;365:1543-1551.

13. Allen NE, Tsilidis KK, Key TJ, et al. Menopausal hormone therapy and risk of endometrial carcinoma among postmenopausal women in the European Prospective Investigation Into Cancer and Nutrition. Am J Epidemiol 2010;172: 1394-1403.

14. Anderson GL, Judd HL, Kaunitz AM, et al. Effects of estrogen plus progestin on gynecologic cancers and associated diagnostic procedures: The Women's Health Initiative randomized trial. JAMA 2003;290:1739-1748.

15. Howlader N, Noone AM, Krapcho M, et al. SEER Cancer Statistics Review (CSR) 1975-2014. National Cancer Institute. Bethesda, MD. Available at: https://seer.cancer.gov/csr/1975_ 2014 (https://seer.cancer.gov/csr/1975_2014/). Accessed January 25, 2018.

16. Ziel HK, Finkle WD. Increased risk of endometrial carcinoma among users of conjugated estrogens. N Engl J Med 1975;293:1167-1170.

17. Smith DC, Prentice R, Thompson DJ, Herrmann WL. Association of exogenous estrogen and endometrial carcinoma. N Engl J Med 1975;293:1164-1167.

18. Whitehead MI, Campbell S. Endometrial histology, uterine bleeding, and oestrogen levels in menopausal women receiving oestrogen therapy and oestrogen/progestogen therapy. In: Brush M, Taylor RWT, King RJB, eds. Endometrial cancer. London: Bailliere Tindall, 1978:65-80.

19. Whitehead MI. The effects of oestrogens and progestogens on the postmenopausal endometrium. Maturitas 1978; 1:87-98.

20. Weiss NS, Szekely DR, Austin DF. Increasing incidence of endometrial cancer in the United States. N Engl J Med 1976;294:1259-1262. 
21. Woodruff JD, Pickar JH. Incidence of endometrial hyperplasia in postmenopausal women taking conjugated estrogens (Premarin) with medroxyprogesterone acetate or conjugated estrogens alone. The Menopause Study Group. Am J Obstet Gynecol 1994;170:1213-1223.

22. Chlebowski RT, Anderson GL, Sarto GE, et al. Continuous combined estrogen plus progestin and endometrial cancer: The Women's Health Initiative randomized trial. J Natl Cancer Inst 2016;108:dvj350.

23. The NAMS 2017 Hormone Therapy Position Statement Advisory Panel. The 2017 hormone therapy position statement of The North American Menopause Society. Menopause 2017;24:728-753.

24. Barbaglia G, Macia F, Comas M, et al. Trends in hormone therapy use before and after publication of the Women's Health Initiative trial: 10 years of follow-up. Menopause 2009;16:1061-1064.

25. Steinkellner AR, Denison SE, Eldridge SL, Lenzi LL, Chen $\mathrm{W}$, Bowlin SJ. A decade of postmenopausal hormone therapy prescribing in the United States: Long-term effects of the Women's Health Initiative. Menopause 2012;19: 616-621.

26. Hersh AL, Stefanick ML, Stafford RS. National use of postmenopausal hormone therapy: Annual trends and response to recent evidence. JAMA 2004;291:47-53.

27. Bachmann G, Lobo RA, Gut R, Nachtigall L, Notelovitz M. Efficacy of low-dose estradiol vaginal tablets in the treatment of atrophic vaginitis: A randomized controlled trial. Obstet Gynecol 2008;111:67-76.

28. Bachmann G, Bouchard C, Hoppe D, et al. Efficacy and safety of low-dose regimens of conjugated estrogens cream administered vaginally. Menopause 2009;16:719-727.

29. Simon J, Nachtigall L, Ulrich LG, Eugster-Hausmann M, Gut R. Endometrial safety of ultra-low-dose estradiol vaginal tablets. Obstet Gynecol 2010;116:876-883.

30. Crandall CJ, Hovey KM, Andrews CA, et al. Breast cancer, endometrial cancer, and cardiovascular events in participants who used vaginal estrogen in the Women's Health Initiative Observational Study. Menopause 2018;25:11-20.

31. Weissfeld JL, Liu W, Woods C, et al. Trends in oral and vaginally administered estrogen use among US women 50 years of age or older with commercial health insurance. Menopause 2018;25:611-614.

32. Gunnison KM, Tucker LY, Postlethwaite DA, Pruett KM. Topical vaginal estrogen use and risk of endometrial hyperplasia or cancer. Obstet Gynecol 2015;125:8S.

33. Manson JE, Kaunitz AM. Menopause managementgetting clinical care back on track. N Engl J Med 2016; 374:803-806.

34. Fishman JR, Flatt MA, Settersten RA, Jr. Bioidentical hormones, menopausal women, and the lure of the "natural" in U.S. anti-aging medicine. Soc Sci Med 2015;132: 79-87.

35. American College of Obstetricians and Gynecologists. Compounded bioidentical menopausal hormone therapy. Committee Opinion No. 532. Obstet Gynecol 2012;120: 411-415.

36. Huffman DCRP, Holmes ERPM. Specialty compounding for improved patient care: A national survey of compounding pharmacists. Int J Pharm Compd 2006;10:462468.

37. Huffman DC, Holmes ER. Specialty compounding for improved patient care: 2006 national survey of compounding pharmacists. Int J Pharm Compd 2008;12:74-82.
38. McPherson T, Fontane P, Iyengar R, Henderson R. Utilization and costs of compounded medications for commercially insured patients, 2012-2013. J Manag Care Spec Pharm 2016;22:172-181.

39. Pinkerton J, Constantine G. Compounded non-FDAapproved menopausal hormone therapy prescriptions have increased: Results of a pharmacy survey. Menopause 2016; 23:359-367.

40. Pinkerton J, Santoro N. Compounded bioidentical hormone therapy: Identifying use trends and knowledge gaps among US women. Menopause 2015;22:926-936.

41. Gass ML, Stuenkel CA, Utian WH, et al. Use of compounded hormone therapy in the United States: Report of The North American Menopause Society Survey. Menopause 2015;22:1276-1284.

42. Davis R, Batur P, Thacker HL. Risks and effectiveness of compounded bioidentical hormone therapy: A case series. J Womens Health (Larchmt) 2014;23:642-648.

43. Eden JA, Hacker NF, Fortune M. Three cases of endometrial cancer associated with "bioidentical" hormone replacement therapy. Med J Aust 2007;187:244-245.

44. Dezman VL, Gersak MZ, Gersak K. Two case of atypical endometrial hyperplasia associated with "bioidentical" hormone replacement therapy: IGCS-0084 Uterine Cancer, including Sarcoma. Int J Gynecol Cancer 2015;25 Suppl 1:71.

45. Chang SC, Lacey JV, Jr, Brinton LA, et al. Lifetime weight history and endometrial cancer risk by type of menopausal hormone use in the NIH-AARP diet and health study. Cancer Epidemiol Biomarkers Prev 2007;16:723-730.

46. Calle EE, Rodriguez C, Walker-Thurmond K, Thun MJ. Overweight, obesity, and mortality from cancer in a prospectively studied cohort of U.S. adults. N Engl J Med 2003;348:1625-1638.

47. Bergstrom A, Pisani P, Tenet V, Wolk A, Adami HO. Overweight as an avoidable cause of cancer in Europe. Int $\mathbf{J}$ Cancer 2001;91:421-430.

48. Setiawan VW, Yang HP, Pike MC, et al. Type I and II endometrial cancers: Have they different risk factors? J Clin Oncol 2013;31:2607-2618.

49. Key TJ, Pike MC. The dose-effect relationship between 'unopposed' oestrogens and endometrial mitotic rate: Its central role in explaining and predicting endometrial cancer risk. Br J Cancer 1988;57:205-212.

50. National Center for Health Statistics. Prevalence of overweight, obesity, and extreme obesity among adults: United States, 1960-1962 through 2011-2012. September 2014. Available at: https://www.cdc.gov/nchs/data/hestat/obesity_ adult_11_12/obesity_adult_11_12.htm Accessed December $1,2017$.

51. National Center for Health Statistics. Table 58 (page 1 of 7). Normal weight, overweight, and obesity among adults aged 20 and over, by selected characteristics: United States, selected years 1988-1994 through 2011-2014. Available at: https://www.cdc.gov/nchs/data/hus/2015/058.pdf Accessed December 1, 2017.

52. Friberg E, Orsini N, Mantzoros CS, Wolk A. Diabetes mellitus and risk of endometrial cancer: A meta-analysis. Diabetologia 2007;50:1365-1374.

53. Geiss LS, Wang J, Cheng YJ, et al. Prevalence and incidence trends for diagnosed diabetes among adults aged 20 to 79 years, United States, 1980-2012. JAMA 2014;312: 1218-1226.

54. Ziskoven C, Jager M, Kircher J, et al. Physiology and pathophysiology of nitrosative and oxidative stress in os- 
teoarthritic joint destruction. Can J Physiol Pharmacol 2011;89:455-466.

55. McPherson CP, Sellers TA, Potter JD, Bostick RM, Folsom AR. Reproductive factors and risk of endometrial cancer. The Iowa Women's Health Study. Am J Epidemiol 1996; 143:1195-1202.

56. Karageorgi S, Hankinson SE, Kraft P, De VI. Reproductive factors and postmenopausal hormone use in relation to endometrial cancer risk in the Nurses' Health Study cohort 1976-2004. Int J Cancer 2010;126:208-216.

57. Ghanbari Andarieh M, Agajani Delavar M, Moslemi D, Esmaeilzadeh S. Risk factors for endometrial cancer: Results from a Hospital-Based Case-Control Study. Asian Pac J Cancer Prev 2016;17:4791-4796.

58. Cabrera SM, Bright GM, Frane JW, Blethen SL, Lee PA. Age of thelarche and menarche in contemporary US females: A cross-sectional analysis. J Pediatr Endocrinol Metab 2014; 27:47-51.

59. Chumlea WC, Schubert CM, Roche AF, et al. Age at menarche and racial comparisons in US girls. Pediatrics 2003;111:110-113.

60. Monte LM, Ellis RR. Fertility of women in the United States: 2012 population characteristics. Hyattsville, MD. Available at: https://www.census.gov/content/dam/Census/ library/publications/2014/demo/p20-575.pdf Accessed October 2017.

61. Mosher WD, Jones J. Use of contraception in the United States: 1982-2008. Available at: https://www.cdc.gov/nchs/ data/series/sr_23/sr23_029.pdf Accessed October 2017.

62. Kavanaugh ML, Jerman J. Contraceptive method use in the United States: Trends and characteristics between 2008, 2012 and 2014. Contraception 2018;97:14-21.

63. Iversen L, Sivasubramaniam S, Lee AJ, Fielding S, Hannaford PC. Lifetime cancer risk and combined oral contraceptives: The Royal College of General Practitioners' Oral Contraception Study. Am J Obstet Gynecol 2017;216: 580.e581-580.e589.

64. Collaborative Group on Epidemiological Studies on Endometrial Cancer. Endometrial cancer and oral contraceptives: An individual participant meta-analysis of 27276 women with endometrial cancer from 36 epidemiological studies. Lancet Oncol 2015;16:1061-1070.

65. Dossus L, Allen N, Kaaks R, et al. Reproductive risk factors and endometrial cancer: The European Prospective Investigation into Cancer and Nutrition. Int J Cancer 2010; 127:442-451.

66. Mueck AO, Seeger H, Rabe T. Hormonal contraception and risk of endometrial cancer: A systematic review. Endocr Relat Cancer 2010;17:R263-R271.

67. Beining RM, Dennis LK, Smith EM, Dokras A. Metaanalysis of intrauterine device use and risk of endometrial cancer. Ann Epidemiol 2008;18:492-499.

68. Branum AM, Jones J. Trends in long-acting reversible contraception use among U.S. women aged 15-44. NCHS Data Brief 2015:1-8.

69. Pal N, Broaddus RR, Urbauer DL, et al. Treatment of lowrisk endometrial cancer and complex atypical hyperplasia with the levonorgestrel-releasing intrauterine device. Obstet Gynecol 2018;131:109-116.

70. Jamieson S, Fuller PJ. Molecular pathogenesis of granulosa cell tumors of the ovary. Endocr Rev 2012;33:109-144.
71. National Cancer Institute. SEER Cancer Statistics Review 1975-2014; Cancer of the Ovary. Available at: https:// seer.cancer.gov/csr/1975_2014/results_merged/sect_21_ovary. pdf Accessed December 1, 2017.

72. Fisher B, Costantino JP, Wickerham DL, et al. Tamoxifen for the prevention of breast cancer: Current status of the National Surgical Adjuvant Breast and Bowel Project P-1 study. J Natl Cancer Inst 2005;97:1652-1662.

73. Waters EA, Cronin KA, Graubard BI, Han PK, Freedman AN. Prevalence of tamoxifen use for breast cancer chemoprevention among U.S. women. Cancer Epidemiol Biomarkers Prev 2010;19:443-446.

74. Cust AE, Armstrong BK, Friedenreich CM, Slimani N, Bauman A. Physical activity and endometrial cancer risk: A review of the current evidence, biologic mechanisms and the quality of physical activity assessment methods. Cancer Causes Control 2007;18:243-258.

75. Voskuil DW, Monninkhof EM, Elias SG, et al. Physical activity and endometrial cancer risk, a systematic review of current evidence. Cancer Epidemiol Biomarkers Prev 2007; 16:639-648.

76. Moore SC, Gierach GL, Schatzkin A, Matthews CE. Physical activity, sedentary behaviours, and the prevention of endometrial cancer. Br J Cancer 2010;103:933938.

77. An R, Xiang X, Yang Y, Yan H. Mapping the prevalence of physical inactivity in U.S. States, 1984-2015. PLoS One 2016;11:e0168175.

78. American College of Obstetricians and Gynecologists Committee on Gynecologic Practice, American Society for Reproductive Medicine Practice Commitee. Compounded bioidentical menopausal hormone therapy. Fertil Steril 2012;98:308-312.

79. Kock NB, van TE, Oyen WJ, Wymenga AB, van Susante JL. Bone scintigraphy after osteochondral autograft transplantation in the knee: 13 patients followed for 4 years. Acta Orthop 2010;81:206-210.

80. Mahaguna V, McDermott JM, Zhang F, Ochoa F. Investigation of product quality between extemporaneously compounded progesterone vaginal suppositories and an approved progesterone vaginal gel. Drug Dev Ind Pharm 2004;30:1069-1078.

81. Ramin CJ. The hormone hoax thousands fall for. More.com. October 2013, 134-156.

82. Files JA, Ko MG, Pruthi S. Bioidentical hormone therapy. Mayo Clin Proc 2011;86:673-680.

83. Boothby LA, Doering PL, Kipersztok S. Bioidentical hormone therapy: A review. Menopause 2004;11:356-367.

84. Santoro N, Braunstein GD, Butts CL, Martin KA, McDermott M, Pinkerton JV. Compounded bioidentical hormones in endocrinology practice: An Endocrine Society Scientific Statement. J Clin Endocrinol Metab 2016;101: 1318-1343.

Address correspondence to:

Ginger D. Constantine, MD

EndoRheum Consultants, LLC 212 Mine Road Malvern, PA 19355

E-mail: endorheum@gmail.com 